\title{
The School's Role in Enhancing Intellectual Security from the Viewpoint of the Teachers of the Kasbah of Salt
}

\author{
Khloud Fallah Ahmad Rahamneh \\ AL-Balqa Applied University, Princess Rahma University, Jordan
}

\begin{abstract}
This study aimed to know the school's role in enhancing intellectual security from the point of view of the teachers of the Kasbah of Salt. The study population consisted of all the teachers of the Qasaba of Salt, who numbered 2,452 teachers according to the statistics of the Ministry of Education for the year 2020, while the sample consisted of (500 A male and female teacher from the study population by the simple random method, and with a percentage $(20 \%)$ of the size of the study population, they were chosen according to the simple random method, the descriptive survey methodology was followed. A questionnaire prepared for this purpose was used.The results of the study highlighted the prominent role of the school in enhancing intellectual security from the point of view of the teachers of the Kasbah of Salt, where the total arithmetic mean of all paragraphs of the questionnaire was (4.034) and of high relative importance. The results of the study highlighted the prominent role of the school in enhancing intellectual security from the point of view of the teachers of the Kasbah of Salt, where the total arithmetic mean of all paragraphs of the questionnaire was (4.034) and of high relative importance.
\end{abstract}

Keywords: intellectual security, strengthening, school, salt

DOI: $10.7176 / \mathrm{JEP} / 12-6-09$

Publication date: February $28^{\text {th }} 2021$

\section{Introduction}

Security of all kinds is a necessity of life, a fundamental pillar for building societies and securing their individuals and interests, and a fundamental pillar in stabilizing stability, which in turn will be reflected in all political, economic, social and cultural fields.

Intellectual security is an integral part of the concept of comprehensive security. Rather, some believe that intellectual security takes precedence over other types of security due to its importance and because breaching it affects other aspects of security.

The beginnings of the emergence of interest in the concept of intellectual security go back to the beginnings of the third millennium and to the profound transformations witnessed by the world that brought about radical changes in the areas of contemporary life and political, social, communication and cultural challenges that all constitute life data that are reflected in the material, intellectual and moral movement of society as a result of the massive explosion of knowledge and the development of media And the communications revolution and its rapid transfer of multiple forms and models of ideas and cultures from one society to another.

It was natural for all these data to produce a number of changes in the Arab reality, which were reflected in the way of life, thinking, prevailing values and various aspects of life, which led to changes in all social, economic, political and cultural levels (Fadi Ismail, 2003)

Intellectual security in particular has become an important requirement that states seek, because intellectual security concerns the stock of human memory of cultures, principles, values and religious foundations, as well as intellectual security seeks to preserve cultural identity and achieve reassurance of the components of authenticity and acquired culture (Al-Hazmi, 2009)

From here emerges the vital role that social and educational institutions play in order to lay the foundations for achieving intellectual security through the various activities that these institutions undertake that contribute to establishing and achieving intellectual security (Al-Anzi)

The role that the school plays in order to prevent intellectual deviation through curricula, teachers, school radio, and extracurricular and multiple activities is one of the important roles that contribute side by side to establishing the principles of intellectual security in the souls of individuals and their upbringing based on pride in the cultural heritage and arming itself with the values, principles and teachings of the Islamic religion Samha.

\section{The study Problem:}

The problem of the study is represented in contributing to the preservation of Arab culture and the moderation and moderation of Islam, in addition to consolidating the value and ethical system that students receive from their community, in addition to what has been mentioned. Social upbringing institutions play an important role in preventing intellectual deviation by laying foundations that enhance intellectual security of individuals 


\section{The importance of the study:}

- The importance of the study is highlighted by its results, which it is hoped will benefit the following sectors:

- Education to develop curricula that reinforce concepts of intellectual security

- Researchers and those interested in this field by contributing to laying foundations that contribute to the preservation of Arab culture

- Security agencies by spreading awareness programs

Purpose of the study:

The study aims to clarify the school's role in enhancing intellectual security from the viewpoint of the teachers of the Kasbah of Salt

\section{Theoretical framework}

Intellectual security is a supreme necessity and a divine gift that all societies seek, because it is concerned with the stock of human memory in terms of the tolerant culture, values and teachings of religion. Intellectual security seeks to preserve cultural identity and achieve reassurance on the components of originality in the face of the strange and suspicious intellectual currents that threaten the security of societies and the future of their children.

The concept of intellectual security:

The concept of intellectual security is one of the concepts that has received wide attention because it is centered around the mind. It is a product of the human mind and reflects the identity of societies and their intellectual history. Some defined it as:

Activity and joint measures between the state and society, in order to avoid individuals and groups ideological, intellectual or psychological impurities that are the cause of deviating behavior, ideas and morals from the path of righteousness or a reason for falling into perils (Naseer, 1993)

(Al-Haidar, 2002) believes that intellectual security is ensuring that the thoughts and minds of community members are free of all faults and wrong beliefs that may pose a threat to the state's system and security, with the aim of achieving security and stability in social life through state programs and plans that are based on raising the public awareness of the members of society

While (Al-Sharyari, 2013) defines him the reassurance resulting from hesitation and heart and mental contemplation in light of the correct transmission and a frank mind on the individual and collective levels)

While the researcher believes that intellectual security consists of protecting the cultural identity, establishing tolerant concepts of the Islamic religion, and adhering to the original Arab values.

The importance of intellectual security:

Progress, prosperity and development is a basic requirement that all peoples seek, and it is something that can only be achieved by the existence of a stable secure environment. Intellectual security is considered one of the basic needs, but an important means to enhance security along with other types of security related to political, economic, social and cultural aspects, and a tool to fortify the minds of the people of the nation because they are The only way to build, advance and develop societies

Intellectual security is one of the components of the nation in general, but rather it is the most important, its names, the basis of its existence and its continuation, and it is the blessing that life cannot be straightforward with others, and intellectual security is the highest and basic type of security. Studying everything that affects the integrity and integrity of thought, and working to address the causes of insecurity in society (Al-Juhani, 2004) The importance of intellectual security is evidenced by the following:

1- The mind is a machine of thought and intellectual security relates to the human mind, which is the basis of knowledge and creativity in the various areas of life for building societies and their development.

2- Achieving intellectual security is a protection of the fundamentals, as it stems from its association with the nation's religion, which represents the integrity of the faith, the integrity of behavior, and the strengthening of unity and cohesion among the members of the ummah

3- The importance of the mind and its status, as the mind is the engine of man and the leader of his orientations, and with it man can make his decisions (Al-Hazmi, 2004)

4- Establishing intellectual security is the real entrance to creativity, development and growth. It also protects the youth and society alike from being led by extraneous ideas that seek to distort the minds of individuals and destroy the nation's legacy of thought, history, values and distortion of the Islamic religion.

5- Enhancing intellectual security works to prevent crimes, which leads to a decrease in their rates, which will positively affect society and contribute to its revival (Al-Juhani, 2005)

\section{Goals of Intellectual Security}

Intellectual security is an integral part of the security system in its comprehensive concept. Some believe that the breach of intellectual security leads to a breach of other aspects of security, as it has become an important and fundamental pillar in building societies, their development and growth, and the important means to protect the nation's youth from drifting behind the obscure and intrusive thought that seeks in turn To shading the nation's 
youth, violating the values on which this generation was raised, and desecrating the Islamic religion with poisonous ideas aimed at creating a generation far from its values and religion, a weak generation dominated by conflicting and shadowed intellectual currents. Therefore, the goals of intellectual security are clear through the following:

Intellectual security seeks to preserve the identity of society, as there are constants in the life of each society that represent the basis upon which it is built, and the bonds that bind its members determine their behavior and adapt their reactions to events and make the society its independence and distinction and ensure its survival.

Protecting minds from intellectual invasion, cultural deviation, and religious extremism. Rather, intellectual security goes beyond that to be one of the security imperatives to protect acquisitions and stand against everything that leads to a breach of the security of society (Al-Sharayeri, 2013).

The stages of achieving intellectual security

Achieving intellectual security requires action on several fronts, namely prevention, confrontation and treatment, and each of these stages needs requirements and ingredients

The stage of preventing intellectual deviation: The responsibility of this stage rests with the institutions of socialization, represented by the family, and has a great role, as it is the basic building block of society and responsible for the education of individuals, the school, the university, the media and other institutions responsible for the upbringing of individuals.

Dialogue and discussion stage: This responsibility falls on thought leaders, scholars and researchers, and it is a stage we need in case prevention efforts do not succeed in repelling deviant ideas, whether their source is internally or externally, and which works to attract individuals to it and charge them with this intruder thought.

The stage of reform and treatment: This is done through the disclosure of dialogue and discussion with these intellectually deviant individuals by scientifically and intellectually qualified persons in all disciplines (AlMaliki, 2009)

The school

The school is a social institution and a living cell created by society to achieve goals that have special functions and goals that distinguish them from other social institutions concerned with the upbringing of individuals, so the school's function

The school's function goes beyond providing the individual with information and knowledge to developing the learner's personality in all its physical, mental, emotional, social, spiritual and moral aspects in an integrated manner (Izzat Jaradat and Haifa, 1986)

\section{School definitions}

(Ibrahim Nasir, 2001) defined it as a social institution established by society to undertake the education of the fortune, and it is that institution that is valuable to human civilization.

(Izzat Jaradat and Haifa, 1986) defined it as a regular institution responsible for providing an educational environment that works on developing the personality of the learner in an integrated manner and helping him to integrate into and adapt to the large society.

What is the school and its functions in society?

The importance of the school is highlighted in helping individuals to adapt to society. Moreover, it works to qualify individuals to deal with and adapt to the rapid society. Public life, especially as we began to suffer from intellectual currents affecting the minds of our children

It also preserves the cultural heritage and works to pass it on for generations, so it is one of the school's functions for any community:

1- Developing scientific thinking methods and enhancing self-learning methods

2- Transferring cultural heritage: The school transfers the experiences of nations and previous generations and presents it to individuals in order to expand their horizons and increase their experiences

Simplification and summarization: the school works to simplify the information and knowledge for the pupils in order to comprehend them

Filtering and purification: where the school filters facts, information and knowledge from impurities, errors and fallacies in what is called cultural cleansing

Complete the educational family home assignment

Achieving the students' adaptation with their society by providing them with a single cultural identity that reflects the values of the society

Coordination of the efforts made by other institutions in the upbringing of individuals (Abdullah Al-Rashdan and Na`im Jainani, 1999)

Previous studies:

-Arab Studies

1) The study of Abdulaziz Al-Enezi and Muhammad Salim Al-Zaboun (2013), which suggested educational 
foundations for developing the concept of intellectual security for the secondary stage in the Kingdom of Saudi Arabia from the teachers' own point of view. The study used the descriptive survey approach and the study sample consisted of (1764) male and female students. The study concluded that and the concept of intellectual security for high school students in Saudi Arabia came to an average and a set of proposals were put forward to raise this awareness, including the role of the teacher and his awareness of the importance of educating students about the importance of intellectual security and the role of curricula as well.

2) Al-Harbi study (2011), which aimed to reveal the role of the school administration in reviving the preventive intellectual security of students, and the role of the school administration in the way of intellectual security through its interaction with the family and society. The secondary school for boys from Taif Governorate took over the study that the preventive measures and measures taken by the school administration are medium, and that there are statistically significant differences according to the variable of training courses in favor of those who have had three training courses or more

3) Al-Burai's study (2002) which clarified the educational role of the university in facing extremism and violence among youth. The study used the social survey method of three Egyptian universities and concluded that youth are the pillar of society and that the difference in educational, cultural and intellectual levels is a challenge for youth and that the phenomenon of violence among members of society Al-Masry is caused by weak religious faith and weak institutions' role

4) Abu Hamidi's study (2014), which referred to the family's contribution to intellectual security by strengthening the devotional and moral foundations of the children, and the researcher used the descriptive method in his study. A major role in enhancing intellectual security by raising children on ideological foundations, and the importance of the family's role in inculcating a love of science and developing thinking in order to achieve intellectual security

-Foreign Studies:

1) The Flint study (flynt.1995), which is titled The National Security Approach to the National Security Policy to face the sudden challenges targeting the infrastructure. Designed to face sudden threats, it adopted inappropriate information and theories, and indicated that the global view is not unified to create an effective national security to meet the challenges.

2) The study of Tomlinson (Tomlinson, 2006), which referred to highlighting the role of educational institutions in promoting the principles of intellectual security by integrating cultural and ethical values in the educational curricula. During the dissemination of the concepts of moral and cultural values

Commenting on previous studies:

Previous studies emphasized the importance of intellectual security in enhancing the security of societies and preserving the culture of society and the integrity of its beliefs from every intruder, as well as the importance of the role of all community institutions in carrying out this role and indicated the need to pay attention to youth and fortify them with sound thought because they are the pillar of the future.

Method and procedures

This part deals with a description of the study community, the method for selecting the sample, a description of the study tool, methods for verifying its validity and reliability, as well as a description of the methodology used in the study, and the statistical treatment used in data analysis.

Study methodology:

According to the nature of the study in which the school's role in enhancing intellectual security was studied from the viewpoint of the teachers of the Kasbah of the city of As-Salt, the methodology used in the study is the survey descriptive methodology.

Study population

The study population consisted of all the teachers of the Kasbah of the city of As-Salt, whose number is (2452) male and female teachers according to the Ministry of Education statistics for the year 2020

\section{The study sample:}

A sample consisting of (500) male and female teachers from the study population was selected by a simple random method, and with a percentage of $(20 \%)$ of the size of the study population, the study tool was distributed to them, and after collecting the questionnaires, the number of questionnaires recovered reached (458), and (14) were excluded of them, because of the respondents' incomplete response, and therefore the final sample of the study reached (444) of the Qasabat al-Salt teachers.

Study tool

For the purposes of the study, a questionnaire was developed through a review of the theoretical literature and previous studies that dealt with the subject of concept and enhancing intellectual security. It was formulated in the form of a questionnaire that was finalized from (22) paragraphs. 


\section{Validate the tool}

The tool was presented in its initial form to nine experienced and specialized arbitrators, and they were asked to determine the degree of relevance and comprehensiveness of the paragraphs to measure the area in which those paragraphs were mentioned, the affiliation and clarity of the paragraphs, their linguistic integrity, and mention any proposed amendments and suggest paragraphs they deem necessary and delete unnecessary paragraphs. A standard agreement of $(75 \%)$ was approved by the arbitrator's committee to allow for amendment, deletion and addition, and after returning the tool, the proposed amendments were made that the arbitrators included in their recommendations.

\section{Stability of the tool}

The validity of the three study tool was verified using the Karnbach (Alpha) equation for internal consistency, by applying the tool to (40) male and female teachers, both from the study population and outside the sample, then ensuring internal consistency using the Cronbach equation (Alpha). The values of the stability factor for the paragraphs of the questionnaire (0.81) are considered high and appropriate for the purposes of the study, and the response to the study tool was designed according to the five-point scale according to Likert's five-year model as follows: Strongly agree and have (5) degrees, agree and have (4) degrees, neutral and it has (3) degrees, disagreeing and has (two), strongly disagree, and it has (one) only.

For the purposes of the current study, the level of teachers 'assessments of the school's role in enhancing intellectual security was calculated as follows:

(Upper limit for alternatives - Minimum limit for alternatives) / Number of levels

$(5-1) / 3=1.33$

Accordingly, the relative importance of the paragraph is low, as the average of the paragraphs responses ranges between (1) and (2.33)

The relative importance of the paragraph is moderate, as the average of the paragraphs responses ranges between (2.34) and (3.67)

The relative importance of the paragraph is high, as the average of the paragraph responses ranges between (2.68) and more

Table () shows the amount of the arithmetic mean, the standard deviation, the order and the relative importance of each paragraph of the questionnaire

\begin{tabular}{|c|c|c|c|c|c|}
\hline Parag.no. & Paragraph text & mean & S.D & Arrang. & $\begin{array}{l}\text { Relative } \\
\text { importance }\end{array}$ \\
\hline 1 & $\begin{array}{l}\text { Including a culture of intellectual security in the school } \\
\text { curricula contributes to strengthening the students' } \\
\text { intellectual system }\end{array}$ & 4.24 & 0.72 & 2 & High \\
\hline 2 & $\begin{array}{l}\text { Enhancing communication between home and school in } \\
\text { following up on students' problems contributes to } \\
\text { enhancing intellectual security }\end{array}$ & 4.11 & 0.77 & 6 & High \\
\hline 3 & $\begin{array}{l}\text { Paying attention to the type of activities provided by the } \\
\text { school that contribute to spreading intellectual security } \\
\text { among students }\end{array}$ & 3.79 & 0.63 & 16 & High \\
\hline 4 & $\begin{array}{l}\text { The contribution of the community's religious and cultural } \\
\text { institutions from seminars, lectures and meetings } \\
\text { strengthens the system of intellectual security among the } \\
\text { school's students }\end{array}$ & 4.19 & 0.73 & 3 & High \\
\hline 5 & $\begin{array}{l}\text { Promoting scientific studies of adolescent subcultures } \\
\text { contributes to enhancing intellectual security }\end{array}$ & 3.93 & 0.64 & 14 & High \\
\hline 6 & $\begin{array}{l}\text { Serious study of students 'intellectual and behavioral } \\
\text { problems and developing appropriate solutions contributes } \\
\text { to enhancing students' intellectual security }\end{array}$ & 4.02 & 0.69 & 11 & High \\
\hline 7 & $\begin{array}{l}\text { The contribution of student counseling to solving students' } \\
\text { social and behavioral problems contributes to enhancing } \\
\text { intellectual security }\end{array}$ & 4.10 & 0.75 & 7 & High \\
\hline 8 & $\begin{array}{l}\text { Including Arab culture and history in a way that is } \\
\text { compatible with students' age groups and enhances their } \\
\text { intellectual security }\end{array}$ & 4.12 & 0.68 & 5 & High \\
\hline 9 & $\begin{array}{l}\text { The investment of the school's potential in favor of } \\
\text { religious, cultural and national events contributes to } \\
\text { strengthening the students' intellectual security system }\end{array}$ & 3.79 & 0.61 & 16 & High \\
\hline
\end{tabular}




\begin{tabular}{|c|c|c|c|c|c|}
\hline Parag.no. & Paragraph text & mean & S.D & Arrang. & $\begin{array}{l}\text { Relative } \\
\text { importance }\end{array}$ \\
\hline 10 & $\begin{array}{l}\text { Multiple media play an important role in enhancing } \\
\text { intellectual security by directing short messages and films } \\
\text { that focus on intellectual security and broadcasting them } \\
\text { through schools }\end{array}$ & 4.27 & 0.59 & 1 & High \\
\hline 11 & $\begin{array}{l}\text { The school's openness to society's problems by presenting } \\
\text { them and providing appropriate solutions in enhancing } \\
\text { intellectual security }\end{array}$ & 3.98 & 0.66 & 13 & High \\
\hline 12 & $\begin{array}{l}\text { The teacher's focus on the language of dialogue with } \\
\text { students, especially when discussing social issues, } \\
\text { contributes to enhancing intellectual security }\end{array}$ & 4.02 & 0.71 & 11 & High \\
\hline 13 & $\begin{array}{l}\text { Strengthening the system of values through education } \\
\text { contributes to building an established intellectual system } \\
\text { among students }\end{array}$ & 4.10 & 0.69 & 7 & High \\
\hline 14 & $\begin{array}{l}\text { Qualifying school facilities to practice extracurricular } \\
\text { activities contributes to enhancing intellectual security }\end{array}$ & 4.06 & 0.68 & 9 & High \\
\hline 15 & $\begin{array}{l}\text { The curricula include concepts related to the justice and } \\
\text { moderation of Islam through examples and stories in which } \\
\text { Islamic history has an important role in enhancing } \\
\text { intellectual security }\end{array}$ & 4.09 & 0.78 & 8 & High \\
\hline 16 & $\begin{array}{l}\text { The continuous pursuit of the school in developing pride in } \\
\text { the Islamic heritage and the Arab Islamic civilization has a } \\
\text { great role in enhancing intellectual security }\end{array}$ & 3.92 & 0.63 & 15 & High \\
\hline 17 & $\begin{array}{l}\text { Permanent work by the school through the curricula and } \\
\text { administration to develop a sense of loyalty and belonging } \\
\text { to the Jordanian state, an active role in enhancing } \\
\text { intellectual security }\end{array}$ & 4.11 & 0.54 & 6 & High \\
\hline 18 & $\begin{array}{l}\text { The school's focus on providing individuals with effective } \\
\text { succession skills and respecting the other is an important } \\
\text { role in enhancing intellectual security }\end{array}$ & 4.03 & 0.57 & 10 & High \\
\hline 19 & $\begin{array}{l}\text { The school's role in emphasizing a good example in } \\
\text { developing human relations contributes to enhancing } \\
\text { intellectual security }\end{array}$ & 4.14 & 0.71 & 4 & High \\
\hline 20 & $\begin{array}{l}\text { Activating the role of school administration by spreading } \\
\text { awareness messages and cultural and religious information, } \\
\text { which contributes to enhancing intellectual security }\end{array}$ & 3.75 & 0.82 & 17 & High \\
\hline 21 & $\begin{array}{l}\text { Holding religious and cultural competitions that contribute } \\
\text { to spreading culture and contribute to enhancing } \\
\text { intellectual security }\end{array}$ & 4.01 & 0.79 & 12 & High \\
\hline \multirow[t]{2}{*}{22} & $\begin{array}{l}\text { Training students in the method of dialogue and acceptance } \\
\text { of others contributes to enhancing intellectual security }\end{array}$ & 3.98 & 0.66 & 13 & High \\
\hline & Paragraphs combined & 4.034 & 0.687 & - & High \\
\hline
\end{tabular}

\section{Discuss the results}

It is noted that the paragraph number (10) which states (multiple media play an important role in enhancing intellectual security by directing short messages and films that focus on intellectual security and broadcasting them through schools) has ranked first with an arithmetic mean of (4.27) and a standard deviation of (0.59) With a high relative importance, this is attributed to the importance of the media of all kinds, visual, audio and readable in enhancing intellectual security.

It is noticed that the paragraph number (1) which states (including the culture of intellectual security in the school curricula contributes to strengthening the students' intellectual system) has ranked second with an arithmetic mean of (4.14) and a standard deviation of (0.72) and with a high relative importance due to the importance of including concepts of security The intellectual thought in a deliberate manner in the content of the school curricula for its importance in enhancing the intellectual security of students, as for the paragraph number (4) Which states (the contribution of the community's religious and cultural institutions from seminars, lectures, and meetings that enhances the system of intellectual security among the school's students) ranked third with an arithmetic mean of (4.19) and a standard deviation of (0.73) and a high relative importance. Activities and 
seminars in spreading the culture of intellectual security, pride in Arab culture, and armament with religion to confront different cultural currents.

As for the paragraph number (19) which states (the school's role in emphasizing a valid role model in developing human relations that contributes to enhancing intellectual security) it ranked fourth with an arithmetic mean of (4.24) and a standard deviation of (0.71) and a high relative importance of the importance of a good example. In dealing with intellectual deviation, the paragraph number (8) which states (including Arab culture and Arab history in a way that is compatible with students' age stages and enhances their intellectual security) ranked fifth with an arithmetic mean of (4.12) and a standard deviation of (0.68) and of relative importance. High, and this indicates the importance of this matter in strengthening the students' intellectual system.

As for the two paragraphs with numbers (2) and (17), which state (strengthening communication between home and school in following up on students' problems, which contributes to enhancing intellectual security) and (permanent work by the school through curricula and administration to develop a sense of loyalty and belonging to the Jordanian state, an active role In enhancing intellectual security) they ranked sixth with an arithmetic mean of (4.11) and a standard deviation of (0.77), (o.54) for the two paragraphs with numbers (2) and (17) respectively and of high relative importance due to the prominent role of their faculties in enhancing intellectual security Among students

As for the two paragraphs with numbers (7) and (13) that state (the contribution of student counseling in solving students' social and behavioral problems, which contributes to enhancing intellectual security) and (strengthening the value system through education that contributes to building a solid intellectual system among students) they ranked The seventh has an arithmetic mean of (4.10) and a standard deviation of (0.75) and (0.69) for the two paragraphs with numbers (7) and (13) respectively and of high relative importance because solving problems by the specialist and emphasizing the importance of education in building a value system enhances intellectual security Among students.

As for the paragraph number (15), which states (the curricula include concepts related to the justice and moderation of Islam through examples and stories that Islamic history promotes an important role in enhancing intellectual security), it ranked eighth with an arithmetic mean of (4.09) and a standard deviation of (0.78) With high relative importance to the role that this method plays in enhancing students' intellectual security. Paragraph 14, which states (rehabilitation of school facilities to practice extracurricular activities that contribute to enhancing intellectual security, ranked ninth with an arithmetic mean of 4.06 and a deviation A standard value of (0.68) and of high relative importance because the activation of extracurricular activities in filling free time with activities and volunteer work that serve the community and refine the personality of the student.

As for the paragraph number (18) which states (The school's focus on providing individuals with effective communication skills and respecting the other opinion is an important role in enhancing intellectual security) it ranked tenth with an arithmetic mean of (4.03) and a standard deviation of (0.57) and a high relative importance, due to the importance of Communication and its skills in enhancing intellectual security, and the paragraphs with numbers (6) and (12) which provide for (serious study of students' problems) are occupied. Intellectual and behavioral and appropriate solutions contribute to enhancing the intellectual security of students) and (the teacher's focus on the language of dialogue with students, especially when discussing social issues that contribute to enhancing intellectual security) they ranked eleventh with an arithmetic average of 4.02) and a standard deviation of (0.69), (0.71) for the two paragraphs with numbers (6) and (12) respectively and of high relative importance for the role that constructive dialogue plays in building personalities proud of the Arab and Islamic heritage.

As for the paragraph number (21) which states (holding religious and cultural competitions that contribute to spreading culture and contribute to enhancing intellectual security), it ranked twelfth with an arithmetic mean of (4.01) and a standard deviation of (0.79) and with high relative importance because it contributes to spreading thought The correct, paragraphs (11) and (22) which state (the school's openness to the problems of society by presenting them and providing appropriate solutions in enhancing intellectual security) and (training students in the method of dialogue and accepting the other contributes to enhancing intellectual security) they ranked third A tenth with an arithmetic mean of 3.98) and a standard deviation of (0.66) for the two paragraphs with numbers (11) and (22) in a row and with a high relative importance, this is due to the importance of the school and its positive role in providing appropriate solutions to students' problems and the role of continuous training for students on literature of constructive dialogue in enhancing intellectual security

The paragraph number (5) which states (promoting scientific studies of subcultures in adolescence contributes to enhancing intellectual security) ranked fourteenth with an arithmetic mean of (3.93) and a standard deviation of (0.64) and a high relative importance of the importance of this matter. Paragraph number (16) which states (the continuous pursuit by the school in developing pride in the Islamic heritage and the Arab Islamic civilization, a major role in enhancing intellectual security) has ranked fifteenth with an arithmetic mean of (3.92) and a standard deviation of (0.63) and a high relative importance. 
As for the two paragraphs with numbers (3) and (9), which state (concern with the quality of activities provided by the school, which contribute to spreading intellectual security among students) and (investment of the school's potential for the benefit of religious, cultural and national events contributes to strengthening the students' intellectual security system) They ranked sixteenth with an arithmetic mean of (3.79) and a standard deviation of (0.63) and (0.61) for the two paragraphs with numbers (3) and (9), respectively, with high relative importance.

Finally, the paragraph number (20) which states (activating the role of school administration by spreading educational messages and cultural and religious information that contributes to enhancing intellectual security) was ranked seventeen with an arithmetic mean of (3.75) with a standard deviation of (0.82) and a high relative importance for this. The matter is one of the prominent role in enhancing intellectual security.

\section{Recommendations}

As for the most important recommendations that came out of the study, they revolve around:

1) The importance of reviewing school curricula and the necessity of awareness of the importance of studying Arab and Islamic history and its inclusion in the curricula

2) The importance of activating extracurricular activities and giving attention to volunteer work and making it an integral part in terms of its importance in enhancing intellectual security

3) Pay attention to the role of the school radio in spreading culture among students

4) The need to pay attention to seminars, lectures, and the topics that are raised related to the spread of a culture of intellectual security.

\section{References}

1) Al-Borai, Wafaa (2002), The University's Role in Confronting Intellectual Extremism among Young People, Unpublished PhD thesis, Faculty of Education, Alexandria University, Egypt

2) Abu Hamidi, Ali bin Abdo (2014), The family's contribution to achieving intellectual security (an Islamic educational vision), The Arab Journal of Security Studies and Training, Nayef University for Security Sciences, $30(61)$

3) Ismail, Fadi, (2003), Infrastructure for the use of information and communication technology in education and distance learning, a working paper submitted to the regional symposium on the use of information and communication technologies in education and distance learning that was held in Damascus during the period 1/17/2003

4) Al-Juhani, Ali Bin Fayez, (2004), The Family's Function in Supporting Intellectual Security, Police Thought Journal, UAE 12 (4)

5) Jaradat, Ezzat, Abu Ghazaleh, Haifa, Abdul Latif, Khairy, (1986), Introduction to Education, Amman, the authors, 3rd Edition

6) Al-Harthi, Zaid, (2009) The Role of the Sharia Sciences Curriculum in Promoting Intellectual Security for Third-Year Secondary Students, Unpublished PhD thesis, College of Education, King Abdullah Bin Abdulaziz Library

7) Al-Haidar, Haydar Abd al-Rahman (2002), Intellectual Security in the Face of Intellectual Effects, unpublished PhD thesis, College of Graduate Studies, Police Academy, Egypt.

8) Al-Harbi Sultan bin Mujahid, (2011), The role of school administration in achieving preventive intellectual security among students of secondary school students in Taif Governorate from the point of view of the principals and agents of those schools, an unpublished master's thesis, College of Education, Umm Al-Qura University, Kingdom of Saudi Arabia.

9) Al-Rashdan, Abdullah Wajanini, Naim (1999), Introduction to Education, Amman, Dar Al-Shorouk, Second Edition

10) Al-Shurairi, Nazir Bin Nabil, (2013), Intellectual Security in the Light of the Holy Quran, King Fahd Security College, Studies and Research Center, 1st Edition

11) Al-Enezi, Abdul-Aziz Aqeel and Muhammad Salim Al-Zaboon (2015) Ph.D. thesis entitled Educational foundations proposed for developing the concept of intellectual security among high school students in Saudi Arabia, Dirasat Journal, Educational Sciences, University of Jordan, Volume 42, No. 2.

12) Al-Maliki, Abdul Hafeez Abdullah (2006) Towards a National Strategy to Achieve Intellectual Security in the Face of Terrorism, Unpublished PhD Thesis, Naif Arab University for Security Sciences, Riyadh

13) Nasser, Ibrahim (2010), Foundations of Education, ed. (3), Amman, Dar Ammar for publishing and distribution.

13) Flynt, W. 1995. Red, Gray, and Blue: A Security Environment Approach to National Security Policy Countering Emerging Threats Targeting Critical Infrastructure, Kansas: University of Kansas.

14) Tomlinson, J. 2006. Values: the curriculum of moral education, Online Article, Children and Society Journal, 11 (4): 242- 251. 